\title{
TOXICIDADE DA MistuRA FormuladA DE IMAZETHAPYR E IMAZAPIC SOBRe O AZEvÉm EM FUNÇÃo do TeOR de UMIdAde do SOlo ${ }^{1}$
}

\author{
Injury Caused by the Formulated Mixture of the Herbicide Imazethapyr and Imazapic in \\ Raygrass as Affected by Soil Moisture
}

\author{
AVILA, L.A. ${ }^{2}$, MARCHEZAN, M. ${ }^{3}$, FRANÇOIS, T. ${ }^{3}$, CEZIMBRA, D.M. ${ }^{3}$, SOUTO, K.M..$^{4}$ e \\ REFATTI, J.P. ${ }^{3}$
}

\begin{abstract}
RESUMO - Herbicidas do grupo das imidazolinonas têm, em geral, fraca adsorção ao solo e alta solubilidade em água, e, por isso, os niveis de umidade do solo podem alterar a disponibilidade desses herbicidas e seu efeito sobre culturas suscetiveis. Com o objetivo de comparar o efeito de doses da mistura formulada de imazethapyr + imazapic $\left(75+25\right.$ g i.a. $\left.\mathrm{L}^{-1}\right)$ sobre plantas de azevém, cultivadas em solo com três niveis de umidade, foi realizado um experimento em casa de vegetação, no delineamento em blocos ao acaso com quatro repetições. Os tratamentos foram constituidos pela combinação de sete niveis do fator dose $\left(0,100,200,300,400,600\right.$ e $800 \mathrm{~mL} \mathrm{ha}^{-1}$ do produto formulado), combinados com três niveis do fator umidade do solo $(0,-10$ e $-100 \mathrm{kPa})$. Houve aumento na toxicidade e na taxa de redução da massa da matéria seca das plantas com o aumento nas doses do herbicida, sendo esses efeitos menores em solo com teor de água de $-100 \mathrm{kPa}$. O teor de água no solo altera a toxicidade da mistura formulada de imazethapyr + imazapic sobre o azevém, sendo a cultura mais afetada em solos com maiores niveis de umidade.
\end{abstract}

Palavras-chave: impacto ambiental, Lolium multiflorum, resíduo, persistência.

\begin{abstract}
The imidazolinone herbicides have, in general, low soil sorption and high water solubility, and forthis reason, the levels of soil moisture can affect the availability of these herbicides and their effect on susceptible crops. Aiming at comparing the effect of rates of the formulated mixture of imazethapyr + imazapic $\left(75+25 \mathrm{~g}\right.$ a.i. $\left.\mathrm{L}^{-1}\right)$ on the growth of ryegrass plants in soil with three levels of moisture, an experiment was performed in greenhouse, in a randomized block design with four replications. The treatments were a combination of seven levels of the factor rate $(0,100,200,300,400,600$ and $800 \mathrm{~mL}$ ha-1 of formulated product) combined with three levels of soil moisture factor $(0,-10$ and $-100 \mathrm{kPa})$. There was an increase in injury and reduction of shoot dry weight with increasing rates of the herbicide, with lower effects in soil with-100 kPa moisture content. The water content in soil alters the injury caused by the formulated mixture imazethapyr + imazapic on ryegrass, with this crop being the most affected in soils with higher moisture levels.
\end{abstract}

Keywords: environmental impact, Lolium multiflorum, residue, persistence.

\section{INTRODUÇÃO}

O sistema Clearfield ${ }^{\circledR}$ é uma ferramenta amplamente utilizada na lavoura de arroz irrigado do Rio Grande do Sul para o controle do arroz-vermelho. Esse sistema consiste na aplicação do herbicida composto pela mistura formulada de imazethapyr e imazapic (75 e $\left.25 \mathrm{~g} \mathrm{~L} \mathrm{~L}^{-1}\right)$ em cultivares resistentes à herbicidas do grupo imidazolinonas.

Recebido para publicação em 30.3.2010 e na forma revisada em 17.12.2010.

2 Professor, Dep. de Fitossanidade, Universidade Federal de Pelotas - UFPel, Caixa Postal 354, 96010-900 Pelotas-RS, Brasil, Bolsista CNPq, <laavilabr@gmail.com>; ${ }^{3}$ Acadêmico do Curso de Graduação em Agronomia, Universidade Federal de Santa Maria - UFSM, Santa Maria-RS, Brasil; ${ }^{4}$ Mestranda do Programa de Pós-Graduação em Agronomia, UFSM, Santa Maria-RS, Brasil, Bolsista CAPES. 
Os herbicidas utilizados nesse sistema apresentam longa persistência no solo, podendo atingir meia-vida que varia de 60 a 360 dias para o imazethapyr (Goetz et al., 1990; Mangels, 1991) e cerca de 90 dias para o imazapic (Grymes et al., 1995), podendo ocasionar danos a culturas não tolerantes semeadas em sucessão. Nesse sentido, os herbicidas da familia das imidazolinonas causam toxicidade em beterraba, pimentão e tomate, com redução do crescimento e da produtividade das culturas semeadas após 300 dias da aplicação do produto no solo (Alister \& Kogan, 2005).

No sistema de produção de arroz irrigado do Rio Grande do Sul é comum a utilização do azevém como cultura de inverno, e um possivel efeito residual dos herbicidas sobre o crescimento da forrageira pode ser prejudicial à produção de pastagem.

Em condições de solo de várzea, no Brasil foram detectados efeitos negativos do residual do herbicida composto pela mistura formulada de imazethapyr e imazapic $\left(75+25\right.$ g i.a. $\left.\mathrm{L}^{-1}\right)$ no crescimento e desenvolvimento do arroz irrigado (Fontana et al., 2007; Marchesan et al., 2010), do milho (Pinto et al., 2009c), do sorgo (Pinto et al., 2009b) e do azevém (Pinto et al., 2009a). Contudo, para essa última cultura há dados contrastantes, ora demonstrando efeito negativo, ora o efeito não sendo observado. Esses resultados diferenciados podem ocorrer devido a fatores que afetam a disponibilidade do herbicida para ser absorvido pelas plantas.

As imidazolinonas são fracamente adsorvidas ao solo (Senseman, 2007), sendo a matéria orgânica o principal componente desse processo (Kraemer et al., 2009). Para herbicidas que apresentam fraca sorção ao solo, os niveis de umidade deste podem ser um fator importante na disponibilidade deles às plantas (Green \& Obien, 1969), e o transporte do herbicida no sistema solo-planta é um dos fatores mais importantes que controlam a toxicidade em condições de umidade (Walker, 2006).

Os solos de várzea, por estarem localizados em baixadas, com lençol freático próximo à superficie, podem permanecer por longo período de tempo com alta quantidade de água, porém, devido ao perfil relativamente raso, horizonte semi-impermeável e baixa condutividade hidráulica, o déficit hídrico pode também ser frequente.
Como os níveis de umidade do solo podem alterar a disponibilidade de imazethapyr e imazapic no solo, e como esses herbicidas são usados em arroz, precedendo o cultivo do azevém, realizou-se um experimento com o objetivo de estudar o efeito do nivel de umidade do solo na toxicidade da mistura formulada com esses ingredientes ativos sobre o azevém.

\section{MATERIAL E MÉTODOS}

O trabalho foi conduzido em casa de vegetação do Departamento de Fitotecnia da Universidade Federal de Santa Maria, durante o período de junho a agosto de 2008. O delineamento experimental adotado foi o de blocos ao acaso, em esquema fatorial ( $7 \times 3)$, com quatro repetições. $O$ fator $A$ correspondeu a três níveis de umidade do solo: $0,-10$ e $-100 \mathrm{kPa}$. O fator $\mathrm{B}$ correspondeu à testemunha sem aplicação de herbicidas mais seis doses do herbicida composto pela mistura formulada de imazethapyr e imazapic (75 e 25 g i.a. L $\left.^{1}\right)$ : 0, 100, 200, 300, 400, 600 e $800 \mathrm{~mL} \mathrm{ha}^{-1}$.

O solo utilizado no experimento foi coletado em uma área de várzea sem histórico de aplicação de herbicidas, sendo ele um Planossolo Hidromórfico Eutrófico Arênico de textura média, coletando-se uma camada de $0-10 \mathrm{~cm}$. Previamente à instalação do experimento, foi determinada a curva de retenção de água do solo, utilizada no cálculo da quantidade de água a ser adicionada a cada vaso para atingir as tensões de água previstas nos tratamentos. $\mathrm{O}$ teste foi realizado em câmara de Richards, utilizando-se anéis de $56 \mathrm{~mm}$ de diâmetro e $25 \mathrm{~mm}$ de altura, que foram preenchidos com solo desestruturado. O solo foi saturado com água e submetido às tensões correspondentes. Depois de finalizada a drenagem, foi quantificada a água retida no solo, pelo método gravimétrico, determinando-se a massa de solo úmido e seco em estufa a $100^{\circ} \mathrm{C}$. Foram escolhidas essas tensões de água porque permitem adequada caracterização dos efeitos dos tratamentos e desenvolvimento satisfatório do arroz irrigado (Lee et al., 2004).

Cada unidade experimental foi composta por um vaso de $13 \mathrm{~cm}$ de diâmetro e $1 \mathrm{~L}$ de capacidade, preenchido com $800 \mathrm{~g}$ de solo. Antes do preenchimento dos vasos, o solo foi 
peneirado e adubado conforme as recomendações de adubação para as forrageiras de inverno. A adubação nitrogenada em cobertura foi realizada com ureia aplicada no início do perfilhamento $\left(70 \mathrm{~kg} \mathrm{ha}^{-1}\right.$ de $\left.\mathrm{N}\right)$. Para manutenção dos niveis de umidade dos vasos, foram realizadas pesagens diárias, adicionando-se a quantidade de água necessária para manter o solo nas referidas umidades.

A aplicação do herbicida no solo foi realizada com auxílio de micropipetas, seguida de incorporação uniforme ao solo, deixando-o em repouso por um período de 48 horas. Esse período é suficiente para o equilíbrio dos herbicidas com o solo (Avila, 2005). Após esse período, foi semeado em cada vaso o número de sementes para obter uma população inicial de 400 plantas por metro quadrado. Quando as plantas apresentavam uma folha verdadeira, foi realizado desbaste, deixando-se o correspondente a 300 plantas de azevém por metro quadrado (seis plantas por vaso).

Aos 49 dias após a emergência do azevém, foram avaliados: estatura de plantas, massa da matéria seca da parte aérea das plantas, além da atribuição de notas de toxicidade dos herbicidas às plantas de azevém, com base nos sintomas observados visualmente, usando uma escala de $0 \%$ a $100 \%$, em que $0 \%$ corresponde à ausência de toxicidade e $100 \%$ à morte das plantas. Os resultados de estatura de plantas e massa da matéria seca da parte aérea foram transformados para porcentagem da testemunha, para eliminar o efeito do teor de água no crescimento das plantas.

Os dados foram analisados quanto à homocedasticidade e à normalidade e, em seguida, submetidos à análise de variância. Para avaliação dos efeitos de dose, foram realizadas análises de regressão, utilizando o modelo loglogístico proposto por Seefeldt et al. (1995).

\section{RESULTADOS E DISCUSSÃO}

Houve interação entre os fatores teor de umidade do solo e dose de herbicidas para todas as variáveis analisadas (teste $\mathrm{F}, \mathrm{P} \leq 0,05$ ). Notas mais baixas de toxicidade do herbicida foram observadas em plantas cultivadas em solo com menor teor de água (tensão de água de $-100 \mathrm{kPa}$ ) (Figura 1); a dose necessária do herbicida para causar $50 \%$ de toxicidade $\left(\mathrm{FT}_{50}\right)$, nesse caso, foi estimada em $191 \mathrm{~mL} \mathrm{ha}^{-1}$ (Tabela 1). Em solo com maiores quantidades de água, 0 e $-10 \mathrm{kPa}$, a dose do herbicida estimada para a $\mathrm{FT}_{50}$ foi de 91 e $34 \mathrm{~mL} \mathrm{ha}^{-1}$, respectivamente.

Similarmente às notas de toxicidade, a estatura de plantas também foi influenciada pela dose do herbicida, bem como pelos niveis de umidade do solo; as plantas de azevém cultivadas em solo com baixo teor de umidade $(-100 \mathrm{kPa})$ apresentaram menor redução de estatura de plantas em comparação com as cultivadas em solos nos outros dois niveis de umidade (Figura 2). Em solo a $-100 \mathrm{kPa}$, a dose necessária para reduzir em $50 \%$ a estatura das plantas do azevém (EST ${ }_{50}$ ) foi de $283 \mathrm{~mL} \mathrm{ha}^{-1}$, contrastando com $106 \mathrm{~mL} \mathrm{ha}^{-1}$ a $0 \mathrm{kPa}$ e $39 \mathrm{~mL} \mathrm{ha}{ }^{-1}$ a $-10 \mathrm{kPa}$ (Tabela 1 ). A redução de estatura de plantas após a aplicação desse herbicida é sintoma comumente observado em várias culturas, como o arroz irrigado (Fontana et al., 2007; Marchesan et al., 2010), o azevém (Pinto et al., 2009a), o milho (Pinto et al., 2009c) e o sorgo (Pinto et al., 2009b). A redução da estatura de plantas ocorre provavelmente porque esses herbicidas, além de inibirem a enzima ALS, como um efeito secundário, inibem a divisão celular dos pontos de crescimento das plantas, como observado no sistema radicular de batata (Spackman \& Cobb, 1999).

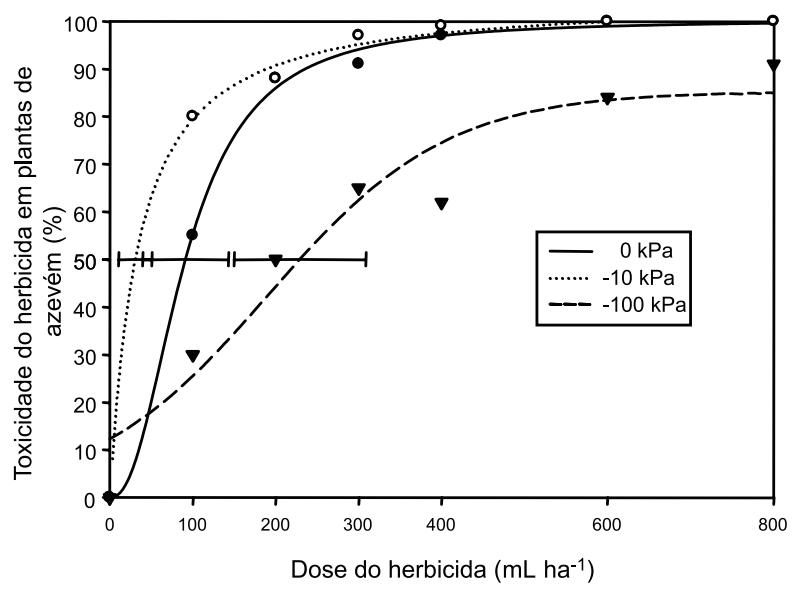

Figura 1 - Efeito do teor de umidade do solo e da dose do herbicida composto pela mistura formulada de imazethapyr e imazapic ( 75 e 25 g i.a. $\mathrm{L}^{-1}$ ) presente no solo na toxicidade dos herbicidas sobre as plantas de azevém avaliadas aos 49 dias após a emergência das plantas. Barras de erro correspondem ao intervalo de confiança em 95\% de probabilidade de erro da dose que causa $50 \%$ de toxicidade no azevém $\left(\mathrm{FT}_{50}\right)$. Santa Maria-RS, 2008. 
Tabela 1 - Parâmetros estimados para as equações de resposta do azevém às doses da mistura formulada de imazethapyr + imazapic ( 75 e 25 g i.a. ha ${ }^{-1}$ ) presente no solo e aos diferentes níveis de umidade do solo. Santa Maria-RS, 2008

\begin{tabular}{|c|c|c|c|c|c|c|}
\hline $\begin{array}{l}\text { Tensões de água } \\
\text { no solo }\end{array}$ & a & $\mathrm{b}$ & $\mathrm{x}_{0}$ & $\mathrm{R}^{2}$ & $\mathrm{P}$ & Equação \\
\hline & \multicolumn{6}{|c|}{ Parâmetros para toxicidade } \\
\hline $0 \mathrm{kPa}$ & $\begin{array}{l}100,3016 \\
(1,6349)^{\frac{1}{}}\end{array}$ & $\begin{array}{c}-2,2904 \\
(-7,9991)\end{array}$ & $\begin{array}{c}91,3636^{2 /} \\
(26,4086)\end{array}$ & 0,9972 & 0,0001 & Logística $^{3 /}$ \\
\hline$-10 \mathrm{kPa}$ & $\begin{array}{r}104,9335 \\
(4,7778) \\
\end{array}$ & $\begin{array}{l}-1,0400 \\
(0,3863)\end{array}$ & $\begin{array}{c}33,5792 \\
(10,2684)\end{array}$ & 0,9972 & 0,0001 & Logística \\
\hline \multirow[t]{2}{*}{$-100 \mathrm{kPa}$} & $\begin{array}{c}85,2870 \\
(7,8508)\end{array}$ & $\begin{array}{c}107,5877 \\
(36,4179)\end{array}$ & $\begin{array}{c}191,6652 \\
(40,5928)\end{array}$ & 0,8983 & 0,0011 & Sigmoidal $^{4 /}$ \\
\hline & \multicolumn{6}{|c|}{ Parâmetros para estatura de plantas } \\
\hline $0 \mathrm{kPa}$ & $\begin{array}{r}100,2249 \\
(3,5604)\end{array}$ & $\begin{array}{c}2,0920 \\
(0,2504)\end{array}$ & $\begin{array}{r}105,6294^{\frac{5}{}} \\
(7,5576)\end{array}$ & 0,9587 & 0,0001 & Logística \\
\hline$-10 \mathrm{kPa}$ & $\begin{array}{c}99,8748 \\
(4,9196)\end{array}$ & $\begin{array}{c}0,9396 \\
(0,2565)\end{array}$ & $\begin{array}{c}38,8896 \\
(18,0443)\end{array}$ & 0,9135 & 0,0001 & Logística \\
\hline \multirow[t]{2}{*}{$-100 \mathrm{kPa}$} & $\begin{array}{l}99,1730 \\
(4,6993)\end{array}$ & $\begin{array}{c}1,2927 \\
(0,1775)\end{array}$ & $\begin{array}{c}282,8954 \\
(32,0167)\end{array}$ & 0,8875 & 0,0001 & Logística \\
\hline & \multicolumn{6}{|c|}{ Parâmetros para massa da matéria seca da parte aérea } \\
\hline $0 \mathrm{kPa}$ & $\begin{array}{r}100,0095 \\
(1,9125)\end{array}$ & $\begin{array}{c}1,9668 \\
(0,1475)\end{array}$ & $\begin{array}{c}90,0018^{6 /} \\
(4,2194)\end{array}$ & 0,9972 & 0,0001 & Logística \\
\hline$-10 \mathrm{kPa}$ & $\begin{array}{c}99,9858 \\
(2,5817) \\
\end{array}$ & $\begin{array}{c}1,0509 \\
(0,2306)\end{array}$ & $\begin{array}{c}23,9317 \\
(10,5030)\end{array}$ & 0,9947 & 0,0001 & Logística \\
\hline$-100 \mathrm{kPa}$ & $\begin{array}{r}101,1535 \\
(7,4395)\end{array}$ & $\begin{array}{c}1,4525 \\
(0,3041)\end{array}$ & $\begin{array}{l}138,2807 \\
(25,0845)\end{array}$ & 0,9497 & 0,0011 & Logística \\
\hline
\end{tabular}

1/ Valores entre parênteses correspondem ao erro-padrão do parâmetro. ${ }^{2 /}$ Dose do herbicida (mL do produto comercial ha $\left.{ }^{-1}\right)$ que causa $50 \%$ de toxicidade $\left(\mathrm{FT}_{50}\right)$ em plantas de azevém; 늘 Equação logística de três parâmetros: $y=\frac{a}{1+\left(\frac{x}{x_{0}}\right)^{b}} ; \underline{4}$ Equação sigmoidal de três parâmetros $y=\frac{a}{1+e^{-\left(\frac{x-x_{0}}{b}\right)}} ;{ }^{5 /}$ Dose do herbicida (mL do produto comercial ha $\left.{ }^{-1}\right)$ que causa $50 \%$ de redução de estatura $\left(\mathrm{EST}_{50}\right)$ de plantas de azevém; ${ }^{6 /}$ Dose do herbicida ( $\mathrm{mL}$ do produto comercial ha-1) que causa $50 \%$ de redução de massa da matéria seca $\left(\mathrm{MS}_{50}\right)$ da parte aérea de plantas de azevém.

Com o aumento da dose dos herbicidas, houve redução da massa de matéria seca da parte aérea de plantas de azevém (Figura 3), que foi maior nas plantas cultivadas no solo com teor intermediário de água $(-10 \mathrm{kPa})$, seguido daquelas que foram cultivadas em solo saturado $(0 \mathrm{kPa})$; as menores reduções de massa seca foram observadas nas plantas cultivadas no solo com menor teor de água $(-100 \mathrm{kPa})$. As doses que causaram $50 \%$ de redução de massa da matéria seca do azevém $\left(\mathrm{MS}_{50}\right)$ foram de 90, 24 e $138 \mathrm{~mL} \mathrm{ha}^{-1}$, respectivamente para as tensões de água no solo de 0, - 10 e -100 kPa (Tabela 1).

Os maiores danos às plantas de azevém observados nos maiores niveis de umidade podem ter sido causados pela maior disponibilidade dos herbicidas na solução do solo. Apesar de não ter sido medido diretamente neste estudo, há maior biodisponibilidade dos herbicidas na solução do solo, com maior quantidade de água no solo, proporcionando maior toxicidade à cultura (Sciumbato et al., 2003; Avila, 2005). Isso é importante para o sistema, pois a quantidade de herbicida disponivel na solução do solo normalmente tem alta correlação com a toxicidade em plantas (Lee et al., 2004).

A maior disponibilidade de herbicidas em solo com maior teor de água ocorre porque, nessas condições, a sorção dos herbicidas é menor, particularmente em solos com baixa 


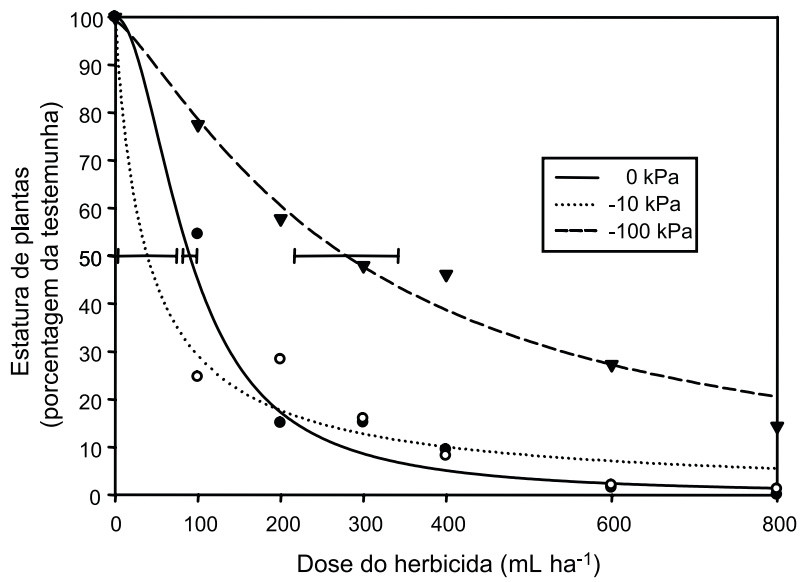

Figura 2 - Efeito do teor de umidade do solo e de doses do herbicida composto pela mistura formulada de imazethapyr e imazapic ( 75 e 25 g i.a. $\mathrm{L}^{-1}$ ) presente no solo sobre a estatura de plantas de azevém avaliadas aos 49 dias após a emergência das plantas. Barras de erro correspondem ao intervalo de confiança em $95 \%$ de probabilidade de erro da dose que causa redução de $50 \%$ da estatura de plantas do azevém $\left(\mathrm{EST}_{50}\right)$. Santa Maria-RS, 2008

capacidade de adsorção ou herbicidas com baixa afinidade com o solo (Green \& Obien, 1969). Resultados semelhantes também foram observados para clomazone, o qual fica mais disponivel e causa maior toxicidade ao arroz irrigado em solos com niveis maiores de umidade (Lee et al., 2004). Comparando os maiores niveis de umidade $(0$ e $-10 \mathrm{kPa})$, nota-se que para as três variáveis analisadas houve maior efeito do herbicida sobre as plantas de azevém cultivadas em solo com - 10kPa. Isso pode ter ocorrido devido ao baixo desenvolvimento do azevém no tratamento com solo saturado. Outro fator que possivelmente pode ter contribuído para o menor efeito do herbicida em condições de menor disponibilidade de água é sua menor absorção em condições de déficit hídrico (Levene \& Owen, 1995; Kogan \& Bayer, 1996).

Os resultados obtidos neste experimento podem explicar, em parte, a variabilidade da resposta do azevém aos herbicidas observada em condições de lavoura, sendo a umidade do solo um fator importante no efeito do herbicida sobre as plantas de azevém. Dessa forma, esses resultados levam a inferir que, em anos chuvosos, a biodisponibilidade dos herbicidas deve ser maior, havendo maior toxicidade inicial sobre as plantas de azevém.

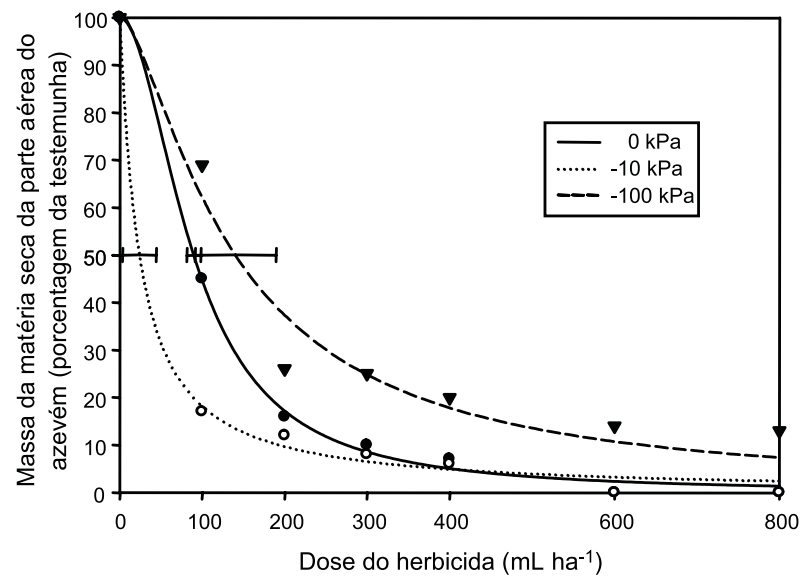

Figura 3 - Efeito do teor de umidade do solo e de doses do herbicida composto pela mistura formulada de imazethapyr e imazapic ( 75 e 25 g i.a. $\mathrm{L}^{-1}$ ) presente no solo sobre a massa da matéria seca da parte aérea de plantas de azevém avaliadas aos 49 dias após a emergência das plantas. Barras de erro correspondem ao intervalo de confiança em $95 \%$ de probabilidade de erro da dose que causa $50 \%$ de redução de massa da matéria seca do azevém $\left(\mathrm{MS}_{50}\right)$. Santa Maria-RS, 2008.

No entanto, outro aspecto importante a ser considerado é que, em solo arenoso e com invernos chuvosos, pode haver maior lixiviação dos herbicidas, levando assim a resultados diferentes do encontrado neste experimento, podendo os herbicidas ser transportados para profundidades maiores no solo, ficando fora da região de absorção das plantas (McDowell et al., 1997; Jourdan et al., 1998).

Os resultados deste experimento permitem concluir que o teor de água no solo influencia a toxicidade do herbicida composto pela mistura de imazethapyr e imazapic sobre a cultura do azevém; solos com maiores teores de umidade provocam maior grau de toxicidade em plantas de azevém.

\section{AGRADECIMENTOS}

À CAPES, pela bolsa de mestrado de Kelen Müller Souto. Ao CNPq, pela bolsa de Produtividade em Pesquisa de Luis Avila e pelo financiamento da pesquisa através do Edital MCT/CNPq 14/2008 Universal, processo 471403/2008-3. À Universidade Federal de Santa Maria, pela estrutura física para realização do experimento. 


\section{LITERATURA CITADA}

ALISTER, C.; KOGAN, M. Efficacy of imidazolinone herbicides applied to imidazolinone-resistant maize and their carryover effect on rotational crops. Crop Protect., v. 24, n. 4 , p. 375-379, 2005.

AVILA, L. A. Imazethapyr: Red rice control and resistance, and environmental fate: Imazethapyr adsorption and availability in three soils as afected by soil moisture contend. 2005. 95 f. Dissertation (Doctor of Phylosophy) - Texas A\&M University, Texas, 2005

FONTANA, L. C. et al. Tolerância de cultivares de arroz irrigado (Oryza sativa) ao herbicida nicosulfuron e à mistura formulada de imazethapyr + imazapic. Planta Daninha, v. 25, n. 4 , p. $791-798,2007$

GOETZ, A. J.; LAVY, T. L.; GEBUR Jr., E. E. Degradation and field persistence of imazethapyr. Weed Sci., v. 38, n. 4/5, p. 421-428, 1990.

GREEN, R. E.; OBIEN, R. S. Herbicide equilibrium in soils in relation to soil water content. Weed Sci., v. 17, n. 4, p. 514-519, 1969.

GRYMES, C. et al. Response of soybean (Glycine max) and rice (Oryza sativa) in rotational to AC 263, 222. Weed Technol., v. 9, n. 3, p.504-511, 1995.

JOURDAN, S. W. et al. Imazethapyr bioactivity and movement in soil. Weed Sci., v. 46, n. 5, p. 608-613, 1998.

KOGAN, M.; BAYER, D. E. Herbicide uptake as influenced by plant water status. Pestic. Biochem. Physiol., v. 56, n. 3, p. 174-182, 1996.

KRAEMER, A. F. et al. Destino ambiental dos herbicidas do grupo das imidazolinonas - revisão. Planta Daninha, v. 27, n. 3, p. 629-639, 2009.

LEE, D.J. et al. Soil characteristics and water potential effects on plant-available clomazone in rice. Weed Sci., v. 52, n. 2 , p. $310-318,2004$.

LEVENE, B. C.; OWEN, M. D. K. Effect of moisture stress and leaf age on bentazon absorption in common cocklebur (Xanthium strumarium) and velvetleaf (Abutilon theophrasti). Weed Sci., v. 43, n. 1, p. 7-12, 1995.
MANGELS, G. Behavior of the imidazolinone herbicides in soil - A review of the literature. In: SHANER, D.; CONNOR, S. (Eds.). The imidazolinone herbicides. Boca Raton: CRC Press, 1991. p. 191-209.

MARCHESAN, E. et al. Carryover of imazethapyr and imazapic to nontolerant rice. Weed Technol., v. 24, n. 1, p. 6-10, 2010.

McDOWELL, R. W. et al. Dissipation of imazapyr, flumetsulam and thifensulfuron in soil. Weed Res., v. 37, n. 6, p. 381-389, 1997.

PINTO, J. J. O. et al. Atividade residual de (imazethapyr+imazapic) sobre azevém anual (Lolium multiflorum), semeado em sucessão ao arroz irrigado, sistema $\operatorname{clearfield}^{\circledR}$. Planta Daninha, v. 27, n. 3, p. 609-619, 2009a.

PINTO, J. J. O. et al. Atividade residual de (imazethapyr+imazapic) para sorgo granífero (Sorghum bicolor) semeado em rotação com o arroz irrigado.

Planta Daninha, v. 27, p. 1015-1024, 2009b. (Numero Especial)

PINTO, J. J. O. et al. Milho (Zea mays) como espécie bioindicadora da atividade residual de (imazethapyr+imazapic). Planta Daninha, v. 27, p. 1005-1014, 2009c. (Numero Especial)

SCIUMBATO, A. S. et al. Plant available imazethapyr in soil solution and red rice (Oryza sativa L.) efficacy as influenced by herbicide rate and soil moisture. In: SOUTHERN WEED SCIENCE SOCIETY ANNUAL MEETING, 56., 2003, Houston. Proceedings... Houston: SWSS, 2003. p. 351.

SEEFELDT, S. S.; JENSEN, J. E. E.; FUERST, E. P. Loglogistic analysis of herbicide dose-response relationship. Weed Technol., v. 9, n. 2, p. 218-227, 1995

SENSEMAN, S. A. Herbicide handbook. 9.ed. Champaign: Weed Science Society of America, 2007. 458 p.

SPACKMAN, V. M.; COBB, A. H. Cell cycle inhibition of potato root tips treated with imazethapyr. Ann. Appl. Biol., v. 135, n. 3 , p. $585-587,1999$.

WALKER, A. Effects of soil moisture content on the availability of soil-applied herbicides to plants. Pestic. Sci., v. 2 , n. 2 , p. $55-69,2006$ 